\title{
Lower Mode Response of Circular Cylinders in Cross-Flow
}

W. W. Durgin

Associate Professor. Mechanical Engineering

\section{P. A. March'}

Lead Engineer. Closed Conduit Flow Section.

Alden Research Laboratory. Worcester Polytechnic Institute, Holden, Mass. 01520

\section{P. J. Lefebvre}

Graduate Research Assistant, Worcester Polytechnic Institute. Worcester, Mass.
Transverse amplitude responses of a circular cylinder in cross-flow were determined as a function of reduced velocities for a variety of spring constants and damping coefficients. Maxima were found at reduced velocities of 5 and 16, and were of comparable amplitude. The first resonance, designated the "fundamental mode," was due to normal vortex street excitation of the spring-mass system. The second resonance, designated the "lower mode," occurred when the natural frequency was approximately one-third of the normal vortex shedding frequency. By assuming that the driving force was sinusoidal, it was possible to evaluate the lift coefficients at resonance. Lift coefficients for the lower mode behaved similarly with amplitude ratio but were an order of magnitude lower than lift coefficients for the fundamental mode. A mechanism was used to oscillate the cylinder transversely at prescribed frequencies and amplitudes. Dominant wake frequencies were determined from a frequency analysis of the hot-wire signal for a range of velocities and a fixed frequency of oscillation. It was found that synchronization of the shedding frequency to the forcing frequency did not take place for the lower mode. The familiar "lock-in" region, or frequency synchronization over finite bandwidth, was observed for the fundamental mode only. Since the frequency associated with normal vortex shedding was not suppressed when oscillations took place in the lower mode, it would seem that a low frequency vortex street had not replaced the normai one. It is likely, then, that the spring-mounted cylinder responded subharmonically to the exciting force resulting from vortex shedding. In this regard, however, it was curious that subharmonic response was not found at a frequency ratio of 0.5 as it was at 0.33 . A conceptual model, which incorporated features of both the low frequency vortex street and subharmonic response, was developed which accounted for lower mode response at a frequency ratio of 0.33 as well as the lack of response at 0.5 .

\section{Introduction}

Circular cylinders exposed to cross-flow are known to experience aerodynamic excitation as a consequence of the Irailing vortex street. When the shedding frequency is near the natural frequency of the mechanical system, lock-in to the latter takes place and vibrations of substantial amplitude can occur if damping is relatively small. For Reynolds numbers above 300 , the phenomenon is characterized by a Strouhal number $\mathrm{S}=f_{s} d / U \approx 0.2$, where the shedding frequency is nearly equal to the natural frequency $f_{s} \approx f_{n}$.

The recent review by King [1] provides a good introduction to the subject of oscillations induced by vortex shedding. Papers by Bishop and Hassan [2], Koopmann [3], Toebes and Ramamurthy [4], Jones [5], and Blevins [6], provide more detailed results, especially with regard to the synchronization of vortex shedding with lateral vibrations of circular cylinders. One notable feature of this phenomenon is that the force

\footnotetext{
Present Position: Mechanical Engineer, Tennessee Valley Authority, Norris, Tenn.

2 Present Position: Product Engineer, Foxboro Company, Foxboro, Mass.

Contributed by the Fluids Engineering Division for publication in the JoURNAL of FLuidS ENGINEERING. Manuscript received by the Fluids
} Engineering Division, January 25, 1979. is directly related to the vortices which are shed alternately from each side of the cylinder with each pair of opposite signs causing one full force cycle. Another is that the ensuing cylinder oscillation substantially affects the vortex shedding process. Near resonance in the fundamental mode (designating phenomena taking place near $S=0.2$ ), the shedding becomes highly organized, longitudinally, and the shedding frequency is entrained to the natural frequency of the spring-mass system. Mathematical models, incorporating essential features of the fluid and mechanical systems, have not been put forth by Hartlen and Currie [7], Skop and Griffin [8], and Iwan and Blevins [9].

Of particular relevance to the present investigation is the possibility of resonance in modes other than the fundamental mode. Various definitions of frequencies associated with the processes involved are defined as follows:

$f_{s}=$ vortex shedding frequency

$f_{s o}=$ vortex shedding frequency for rigidly supported cylinder

$f_{n}=$ natural frequency of mechanical system

$f_{f}=$ frequency of mechanically forced cylinder motion

For the present purposes, the modes are defined as: 


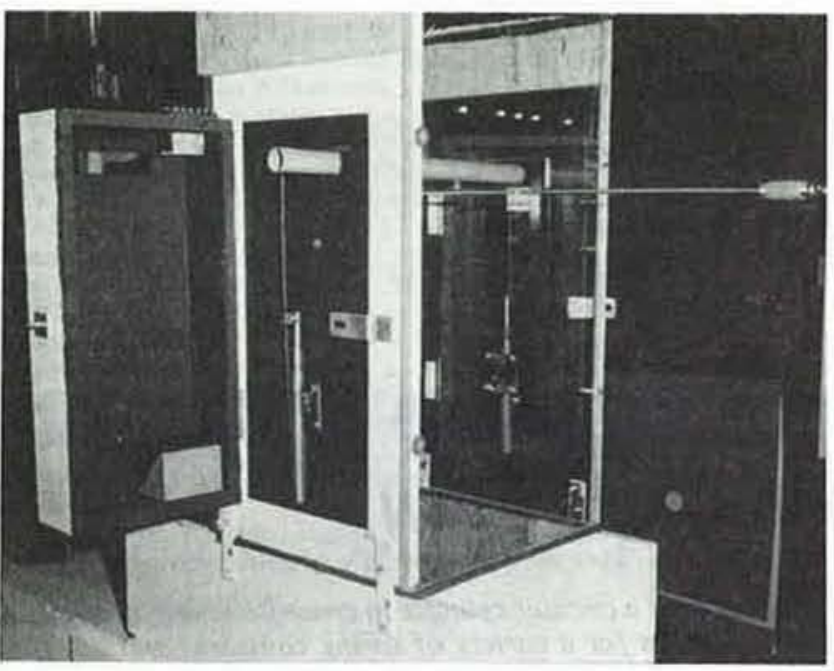

Fig. 1 Elastically mounted cylinder

Higher mode

Fundamental mode

Lower mode

$$
\begin{aligned}
& f_{n}>f_{s o} \\
& f_{n}=f_{s}=f_{s o}(1 \pm \epsilon) \\
& f_{n}<f_{s o}
\end{aligned}
$$

where $\epsilon$ is small and is indicative of the synchronization bandwidth during fundamental mode lock-in. Bishop and Hassan [2] found response in the higher mode (frequency demultiplication, in their terminology) for mechanically oscillated cylinders. Time records of the force in linkage between the oscillation mechanism and the cylinder showed frequency components at $f_{f} / 2$ and $f_{f} / 3$ when the forcing frequency was approximately 2 and 3 times the shedding frequency, respectively. Although this conclusion seems clear from their representative force traces, quantitative evaluation using force measurements of this sort are difficult because of the large inertial contribution to the record.

Toebes [10], by examining hot-wire records of wake velocities behind cylinders undergoing mechanically forced oscillations, also found higher mode response at ratios of 2 and 3. Additionally, he observed lower mode response at a ratio of 0.5 ; that is, the vortex shedding frequency, $f_{s o}$, was approximately twice the cylinder oscillation frequency.

Penzien [11] obtained records of strain from cantilever beams supporting cylinders which could vibrate laterally. While it is not possible to infer amplitude of motion from his published data, lower mode response can be observed for some test cases. The frequency ratio was, at times, near 0.33 although the results are not consistent. In addition, the lower mode response was occasionally larger than the fundamental response.

Lienhard and Liu [12] investigated the frequency of vortex shedding behind a mechanically oscillated cylinder and found indications of lock-in for both higher and lower modes as well as for the fundamental mode. Except for the fundamental mode, the locked-in regions were not distinct. One test series

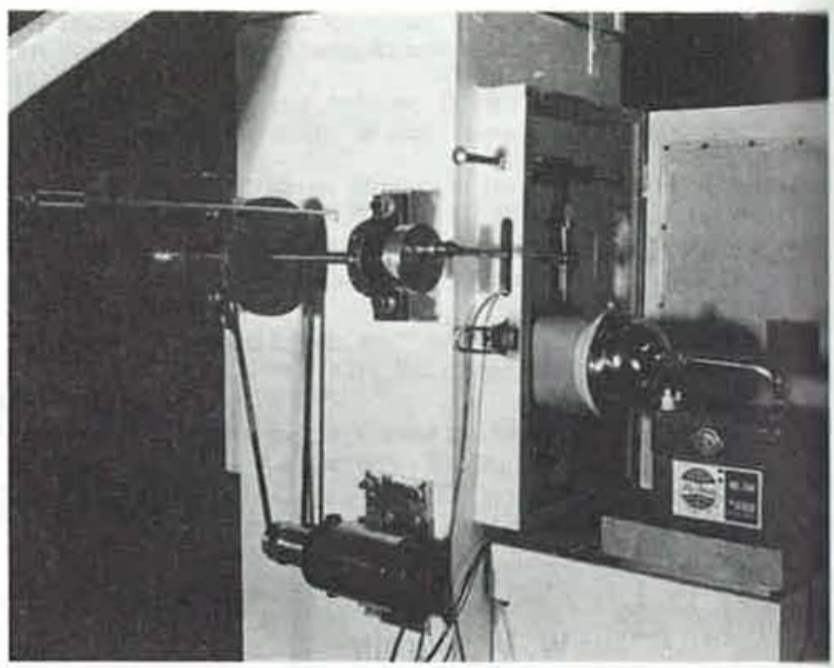

Fig. 2 Mechanically oscillated cylinder

indicated lower mode response at a ratio of 0.55 , while severul showed the higher mode.

Quite by accident, Gowing [13], while investigating the possibility of using lock-in at the fundamental mode as a means of extracting work from a flowing fluid, discoverel that his spring-mounted cylinder was vibrating with large amplitude at a frequency much lower than predicted for normal vortex shedding. The cylinder was mounted on a long. flexible leaf spring at its center and facing upstream in a wind tunnel. The apparatus was designed to produce large amplitude oscillation to facilitate the use of a simple electric generator. It was found that substantially greater oscillation could be maintained in the lower mode than in the fundamental mode, resulting in greater power extraction.

It was hypothesized that a vortex street of low frequenc was either shed directly or formed quickly through coalesence. The latter has been demonstrated experimentally for evolving streets by Taneda [14], and Durgin and Karlsson [15] for single cylinders, while Thomas and Kraus [16] and Zdravkovich [17] made similar findings for multiple cylinder arrangements. Numerical studies by Acton [18] and Christiansen and Zabusky [19] have also exhibited coalesence. Additionally, Griffin and Votaw [20] examined the wakes of laterally vibrated cylinders using smoke visualization demonstrating vortex elongation which precedes vortex fission, although fission was not observed.

Alternatively, the observed response could have been caused by sub-harmonic response of the spring-cylinder system to excitation by the usual vortex street. Two different types of experiments were conducted to help clarify the nature of the observed lower mode response. In the first series of experiments, Stasaitis [21] utilized cylinders which were elastically supported in a manner similar to Gowing's [13]. The apparatus was used to document the phenomenon and explore the effect of various parameters. In the second series

\section{Nomenclature}

\footnotetext{
$a=$ amplitude of cylinder motion

$C_{l}=$ lift coefficient

$d=$ cylinder diameter

$f=$ frequency

$f_{s}=$ vortex shedding frequency

$f_{\text {so }}=$ frequency based on $S=0.2$

$f_{n}=$ natural frequency

$f_{f}=$ frequency of mechanically
}

forced cylinder motion

$M=$ equivalent mass per unit length

$P_{f}=$ spectral density as percent of area under spectrum

$P_{f n}=$ spectral density at $f_{n}$

$P_{f_{s}}=$ spectral density at $f_{s}$

$\mathrm{R}=$ Reynolds number $=U d / \nu$

$\mathrm{S}=$ Strouhal number $=f d / U$

$t=$ time
$U=$ free stream velocity

$U_{r}=$ reduced velocity $=U / f_{n} d$

$x=$ streamwise coordinate

$y=$ lateral coordinate

$\delta_{r}=$ reduced damping

$\delta_{s}=$ logarithmic decrement damping

$\nu=$ kinematic viscosity of fluid

$\rho=$ fluid density

$\tau=$ time constant of exp mechar In the

lixperi

This nection climine mounts lihroug section valve. plastic mount wall. 7 uppros The sli enviro spring mode. ubout bound within varied the lor

To 10 an modu combi freque laken For moun motio stroke with $\mathrm{f}$ again

$\mathrm{Ob}$ perim For $\mathrm{tl}$ analy analy

Resu

Bo Tabl ampl six d respc 
Table 1 Parameters for free vibration tests $(d=2.48 \mathrm{~cm})$

\begin{tabular}{|c|c|}
\hline $\begin{array}{l}\text { Teot } \\
\text { Noo. } \\
\text { No. }\end{array}$ & \\
\hline 1 & \\
\hline 3 & \\
\hline 3 & \\
\hline 3 & \\
\hline 6 & \\
\hline 7 & \\
\hline 8 & \\
\hline 9 & \\
\hline 10 & \\
\hline 11 & \\
\hline 12 & \\
\hline $\begin{array}{l}13 \\
18\end{array}$ & \\
\hline 19 & \\
\hline 20 & \\
\hline 21 & \\
\hline 22 & \\
\hline 23 & \\
\hline 24 & \\
\hline 8rroz & \\
\hline
\end{tabular}

\begin{tabular}{|c|c|c|c|}
\hline $\begin{array}{c}u \\
(\mathrm{~m} / \mathrm{sec})\end{array}$ & $\begin{array}{c}{ }^{\top} \\
\text { (aec) }\end{array}$ & $\begin{array}{c}M \\
(\mathrm{~g}=/ \mathrm{cm})\end{array}$ & $\delta_{8}$ \\
\hline 3.41 & 7.9 & 0.303 & 0.0151 \\
\hline 3.50 & 7.6 & 0.302 & 0.0147 \\
\hline 3.75 & 6.8 & 0.301 & 0.0154 \\
\hline 3.78 & 5.6 & 0.301 & 0.0179 \\
\hline 4.15 & 5.4 & 0.299 & 0.0172 \\
\hline 4.51 & 5.2 & 0.298 & 0.0167 \\
\hline 5.36 & 4.8 & 0.295 & 0.0154 \\
\hline 6.16 & 3.2 & 0.292 & 0.0191 \\
\hline 7.38 & 1.2 & 0.291 & 0.0433 \\
\hline 3.05 & 8.2 & 0.304 & 0.0150 \\
\hline 3.23 & 8.4 & 0.285 & 0.0155 \\
\hline 2.74 & 9.6 & 0.288 & 0.0155 \\
\hline 2.07 & 10.9 & 0.291 & 0.0161 \\
\hline 6.43 & 3.2 & 0.281 & 0.0204 \\
\hline 4.88 & 5.0 & 0.285 & 0.0164 \\
\hline 4.27 & 5.4 & 0.288 & 0.0183 \\
\hline 3.26 & 7.4 & 0.292 & 0.0166 \\
\hline 4.79 & 5.6 & 0.280 & 0.0156 \\
\hline 3.54 & 8.2 & 0.285 & 0.0149 \\
\hline 2.53 & 10.2 & 0.290 & 0.0161 \\
\hline $\pm 0.5 z$ & $21 x$ & $\pm 0.5 x$ & $\pm 1.5 \mathrm{z}$ \\
\hline
\end{tabular}

\begin{tabular}{|c|c|}
\hline${ }_{\mathrm{r}} \mathrm{T}$ & $R$ \\
\hline 1.27 & 5690 \\
\hline 1.23 & 5790 \\
\hline 1.28 & 6250 \\
\hline 1.49 & 6300 \\
\hline 1.42 & 6860 \\
\hline 1.38 & 7520 \\
\hline 1.26 & 8940 \\
\hline 1.55 & 10260 \\
\hline 3.48 & 12300 \\
\hline 1.26 & 5080 \\
\hline 1.22 & 5390 \\
\hline $\begin{array}{l}1.23 \\
\end{array}$ & 4570 \\
\hline $\begin{array}{l}1.30 \\
1.30\end{array}$ & 3460 \\
\hline 1.78 & 10720 \\
\hline 1.45 & 8130 \\
\hline 1.64 & 7110 \\
\hline 1.50 & 5440 \\
\hline 1.21 & 7980 \\
\hline 1.17 & 5890 \\
\hline 1.29 & 4220 \\
\hline 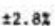 & $\pm 0.9 x$ \\
\hline
\end{tabular}

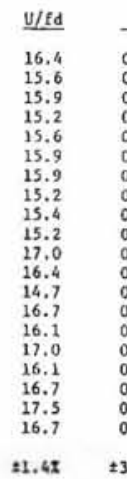

\begin{tabular}{|c|c|}
\hline$a / d$ & $c_{\ell}$ \\
\hline 0.230 & 0.014 \\
\hline 0.184 & 0.011 \\
\hline 0.196 & 0.012 \\
\hline 0.191 & 0.014 \\
\hline 0.159 & 0.011 \\
\hline 0.380 & 0.012 \\
\hline 0.145 & 0.009 \\
\hline 0.129 & 0.010 \\
\hline 0.103 & 0.017 \\
\hline 0.159 & 0.010 \\
\hline 0.134 & 0.008 \\
\hline 0.123 & 0,000 \\
\hline 0.097 & 0.006 \\
\hline 0.104 & 0.009 \\
\hline 0.212 & 0.015 \\
\hline 0.155 & 0.012 \\
\hline 0.165 & 0.012 \\
\hline 0.214 & 0.013 \\
\hline 0.212 & 0.012 \\
\hline 0.120 & 0.008 \\
\hline & \\
\hline
\end{tabular}

of experiments, Lefebvre [22] used a cylinder which was mechanically oscillated and observed the response of the wake in the range of interest.

\section{Experimental Apparatus}

This investigation utilized a vertical wind tunnel with a test section measuring $30 \mathrm{~cm}$ by $30 \mathrm{~cm}$. The vertical orientation climinated static deflection of the cylinders, which were mounted on flexible springs, Fig. 1. Air entered the tunnel through a rounded entrance and proceeded through the test section, a vaned elbow, blower, Venturi meter, and regulating valve. For the first series of experiments, rigid paper and plastic composite cylinders were attached to leaf springs mounted in telescoping clamps on the outside of the tunnel wall. The cylinders passed through slots in the walls so that upproximately $3 \mathrm{~cm}$ on each end were not in the air stream. The slots and telescoping clamps were sealed from the room environment by hinged, air tight boxes. Both cantilever springs vibrated in unison in the fundamental mechanical mode. The frequency of the second mechanical mode was about 30 times the fundamental. Except for the side wall boundary layers, the flow in the test section was uniform within the resolution of the hot-wire. The turbulence intensity varied from 1.7 percent at the highest speed to 6.0 percent at the lowest speed.

To monitor cylinder oscillations, a photo cell was coupled to an amplifier and used to monitor the intensity of light modulated by a shield connected to the spring-cylinder combination. A digital counter was used to determine the frequency of oscillation, and the amplitude of oscillation was taken directly from a storage oscilloscope.

For the second series of experiments, the cylinder was mounted on a mechanism capable of imparting harmonic motion, as shown in Fig. 2. A crankshaft with adjustable stroke was driven through a rubber belt by a stepping motor with feedback speed control. The photo cell arrangement was again used to monitor cylinder motion.

Observation of wake velocities was made for both experimental series using a commercial hot-wire anemometer. For the experiments with forced cylinder oscillation, spectral analysis was performed by tape recording and digitally analyzing the signal on a computer system.

\section{Results}

Both measured and derived parameters for peak lower mode response of elastically mounted cylinders are listed in Table 1. Figure 3 shows the non-dimensional cylinder motion amplitude, $a / d$, versus the reduced velocity, $U_{r}=U / f_{n} d$ for six different natural frequencies, $f_{n}$. The fundamental mode response to vortex shedding is visible as the peaks near $U_{r}=5$
(Strouhal number $\mathrm{S}=0.2$ ). The peak responses are generally somewhat smaller than those obtained by other investigators. The low values of damping and the treatment of the sidewalls probably contribute to this difference. In addition, the peak values are not entirely consistent with the reduced damping values. The reason for this behavior is not presently understood. Additional peaks are apparent near $U_{r}=16$ and reflect substantial oscillatory response to the flowing stream. The reduced velocity at the secondary peak was essentially independent of Reynolds number over the range tested, as can be seen from Fig. 4 . Values of the reduced damping, $\delta_{r}$, were rather small because of the small cylinder mass.

Evidently, in the lower mode, the spring mounted cylinder experienced an exciting force at approximately one-third the normal vortex shedding frequency associated with the flow velocity. By assuming the exciting force to be sinusoidal, the lift coefficient for lower mode resonance could be evaluated. Blevins and Burton (23), for example, give the equation

$$
C_{l}=\delta_{r} \frac{a}{d} \frac{(2 \pi S)^{2}}{\pi}
$$

where $\delta_{r}$ is the reduced damping

$$
\delta_{r}=\frac{2 M \delta_{s}}{\rho d^{2}}
$$

The logarithmic decrement of damping, $\delta_{s}$, was evaluated from vibration decay curves with no air flow, as indicated in Blevins [24]. These values were measured for only a single perturbation from equilibrium so that amplitude dependence was not investigated. The curves, however, appeared exponential. The mass per unit length, $M$, includes the cylinder mass, hydrodynamic mass, and a portion of the spring mass. Here, the Strouhal number is evaluated as the reciprocal of the reduced velocity, $U_{r}$. Figure 5 shows that the lift coefficient increased with amplitude over the experimental range in a manner comparable to that of the fundamental mode. The magnitudes, however, are an order of magnitude less than those associated with typical fundamental mode response.

In the second series of experiments, the $2.48 \mathrm{~cm}$ diameter cylinder was oscillated with an amplitude of $a / d=0.175$ at a frequency of $10.1 \mathrm{~Hz}$. The hot-wire probe was positioned at $x / d=3.0$ and $y / d=1.3$. Velocities at this location were found to provide relatively large power spectral density for both the forcing frequency and vortex shedding frequency over the range of velocities used. Signal analyses were performed such that the frequency range $0-51 \mathrm{~Hz}$ was spanned with a resolution of $0.1 \mathrm{~Hz}$. A low pass filter with a roll-off of $18 \mathrm{db} /$ octave set at $50 \mathrm{~Hz}$ was provided at the input of the $A / D$ converter to eliminate foldover. The output spectra were normalized individually so that the highest peak always 


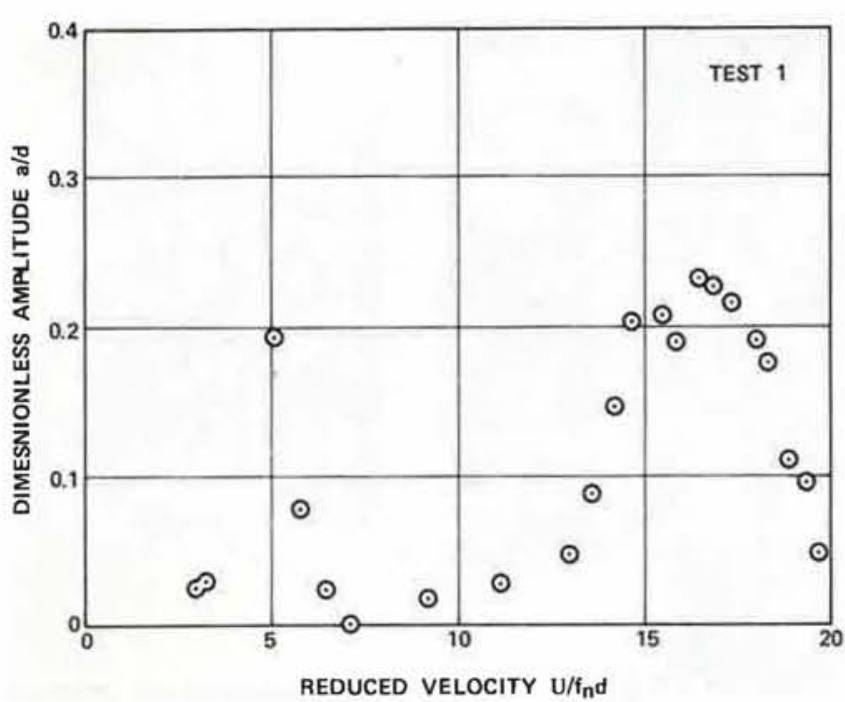

a) $\mathrm{fn}=8.4 \mathrm{~Hz}$

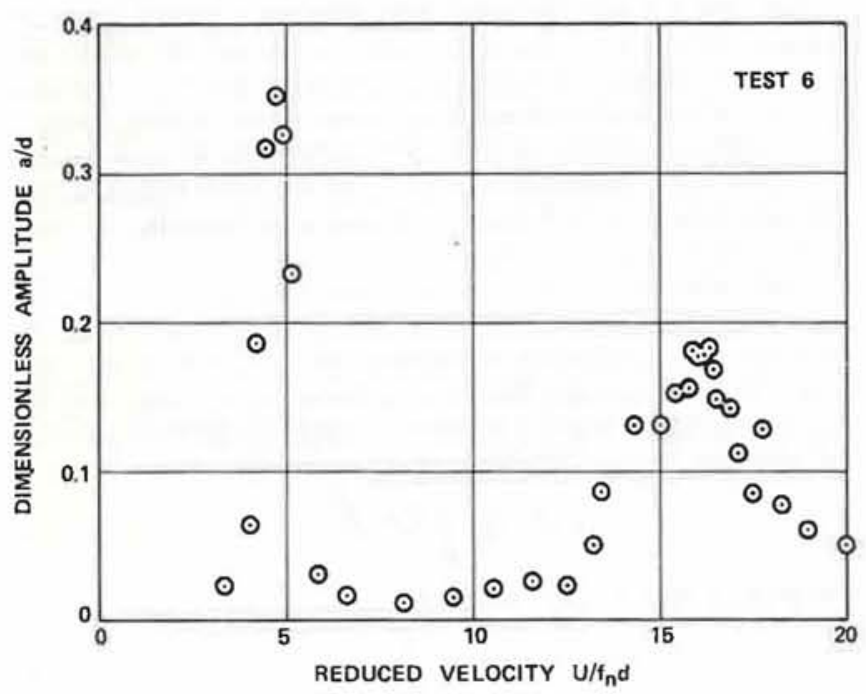

c) $\mathrm{fn}=11.5 \mathrm{~Hz}$

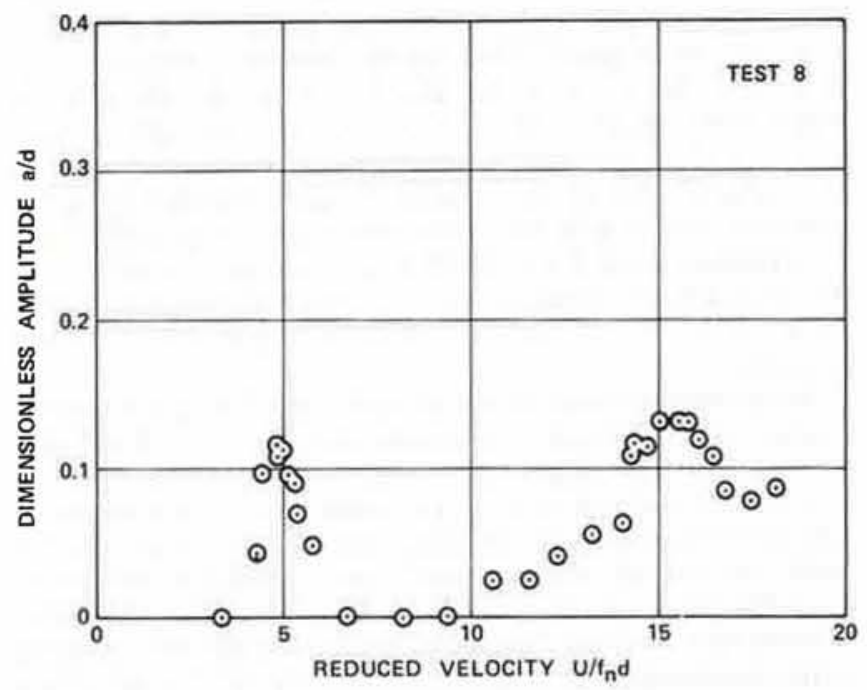

e) $\mathrm{fn}^{=} 16.5 \mathrm{~Hz}$

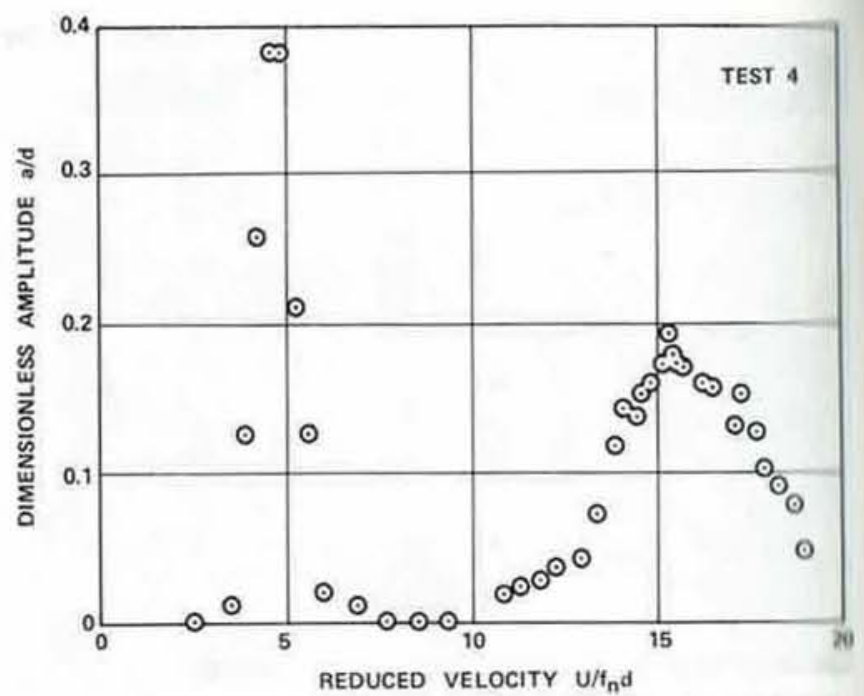

b) fn $=10.0 \mathrm{~Hz}$

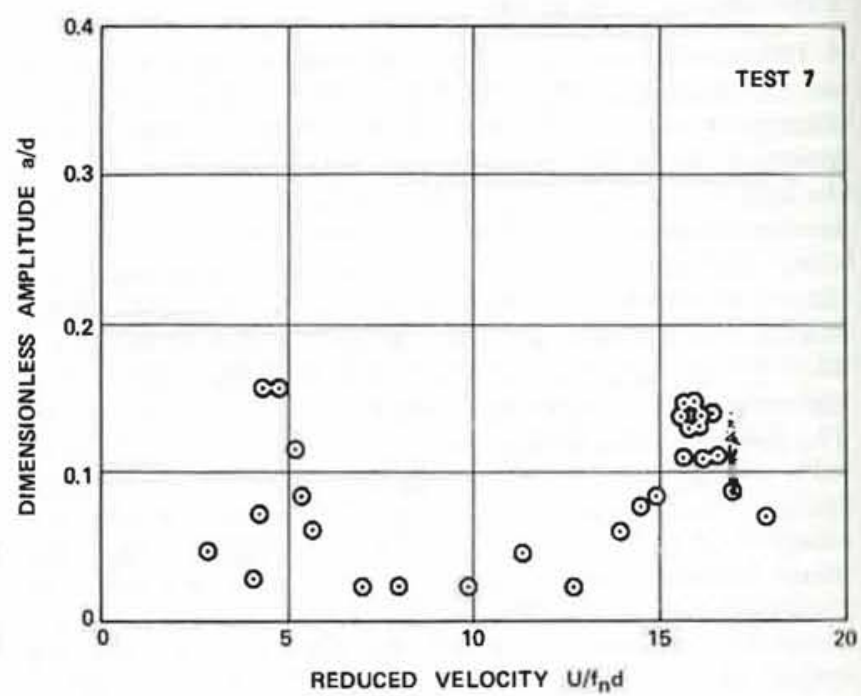

d) $\mathrm{fn}=13.6 \mathrm{~Hz}$

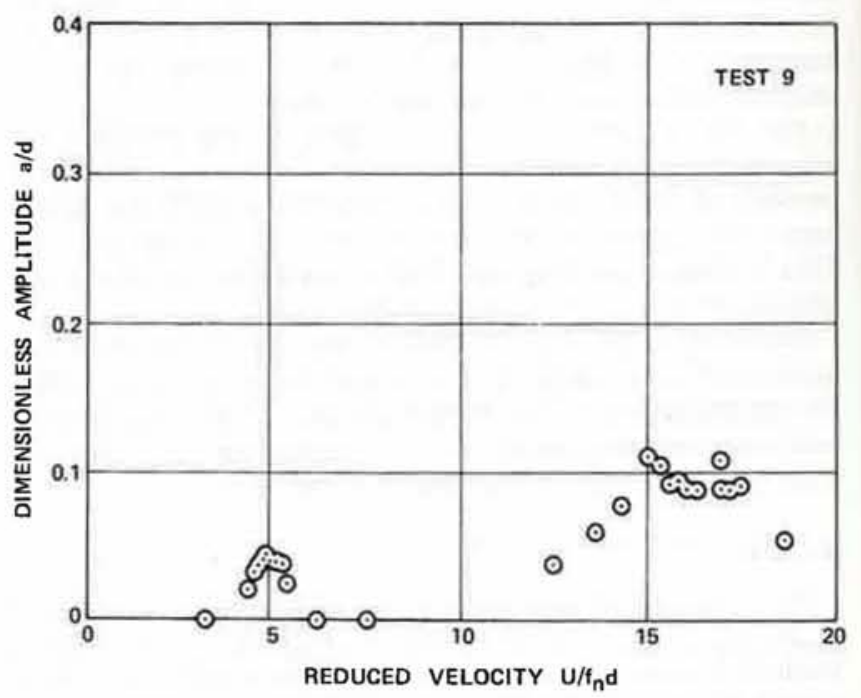

f) $\mathrm{fn}=19.4 \mathrm{~Hz}$

Fig. 3 Amplitude response of elastically mounted cylinders 


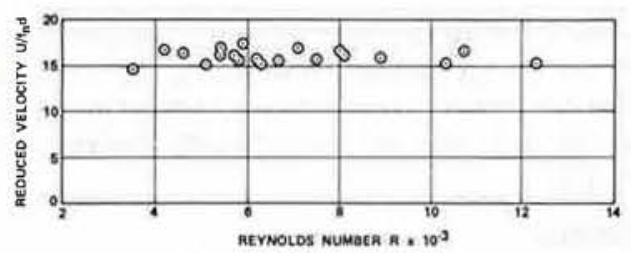

Flg. 4 Reduced velocity of lower mode response versus Reynolds number

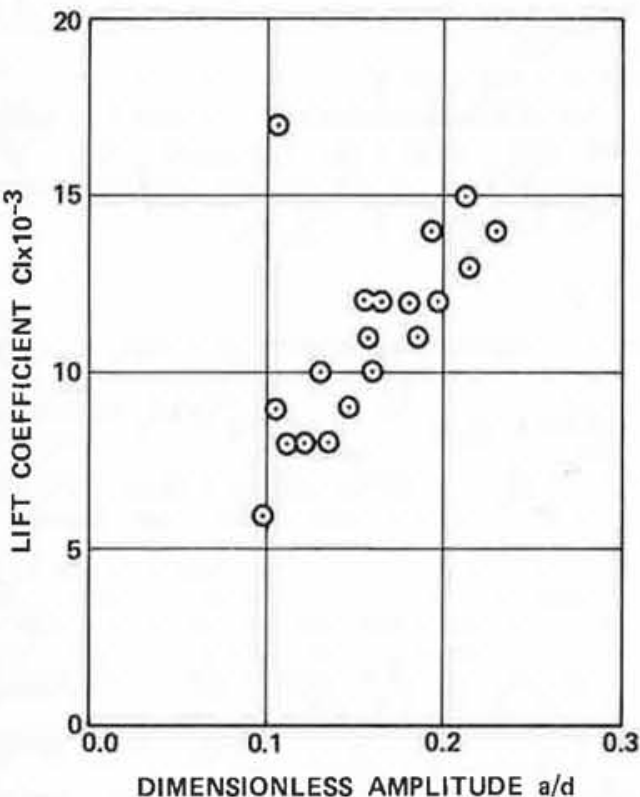

Fig. 5 Lower mode lift coefficient variation with amplitude

plualled full scale on the graphics screen. The value of the likhest peak relative to the integral under the spectrum, $P_{f}$, wits calculated as percent and is tabulated in Table 2 as either $I_{I I I}$ or $P_{f f}$ as appropriate. The Reynolds number, $\mathrm{R}$, and the liequency ratio, $f_{f} / f_{s o}$, are also tabulated.

Figure 6 shows power spectra for various air velocities. In (ii), the shedding frequency is less than the forcing frequency, InIl distinct peaks can be seen for each. Synchronization has licen achieved in $(b)$, and all energy is at $10.1 \mathrm{~Hz}$. In $(c)$, iyuchronization has been lost and the forcing frequency is less Ihiul the shedding frequency. For $f_{f} / f_{s o}=0.5$, $(d)$, subntintial energy can be found at both frequencies. In $(e)$, the fonditions of the freely vibrating cylinder are approached, InId the energy at the forcing frequency is considerably less Iliul at the shedding frequency. For conditions approximately lic same as those for the freely vibrating case, $(f)$, the energy III the forcing frequency is even smaller.

A total of 33 spectra were obtained for Reynolds numbers lielween 1318 and 8697 . The results are summarized in Figure 1 , where lock-in in the fundamental mode can be clearly seen. A l frequency ratios $f_{f} / f_{s o}=0.5$ and 0.33 , distinct lock-in was Int achieved. Both frequencies were, however, clearly present alove the fundamental mode lock-in region.

An error analysis based on direct propagation of estimated ilieusurement inaccuracies was made. Maximum errors, in percents to be associated with derived quantities, are inbulated at the end of Tables 1 and 2 .

\section{IIncussion}

The spring mounted cylinder experienced excitation at $I_{n} / f_{s}=0.33$. Although the lift coefficients were relatively aimuli, the cylinders, nevertheless, experienced substantial
Table 2 Peaks in power spectra

\begin{tabular}{|c|c|c|c|c|}
\hline & $R$ & $f_{f} / f_{s o}$ & $\begin{array}{l}P_{f s o} \\
(\%)\end{array}$ & $\begin{array}{l}P_{f f} \\
(\%)\end{array}$ \\
\hline & $\begin{array}{l}1580 \\
2370 \\
4480 \\
4740 \\
6460 \\
7120\end{array}$ & $\begin{array}{l}1.64 \\
1.00 \\
0.53 \\
0.50 \\
0.36 \\
0.33\end{array}$ & $\begin{array}{r}4.14 \\
32.16 \\
1.97 \\
2.09 \\
2.92 \\
1.41\end{array}$ & $\begin{array}{r}1.76 \\
32.16 \\
3.92 \\
2.14 \\
1.38 \\
0.77\end{array}$ \\
\hline Error & $\pm 0.9 \%$ & $\pm 1.0 \%$ & $\pm 0.5 \%$ & $\pm 0.5 \%$ \\
\hline
\end{tabular}
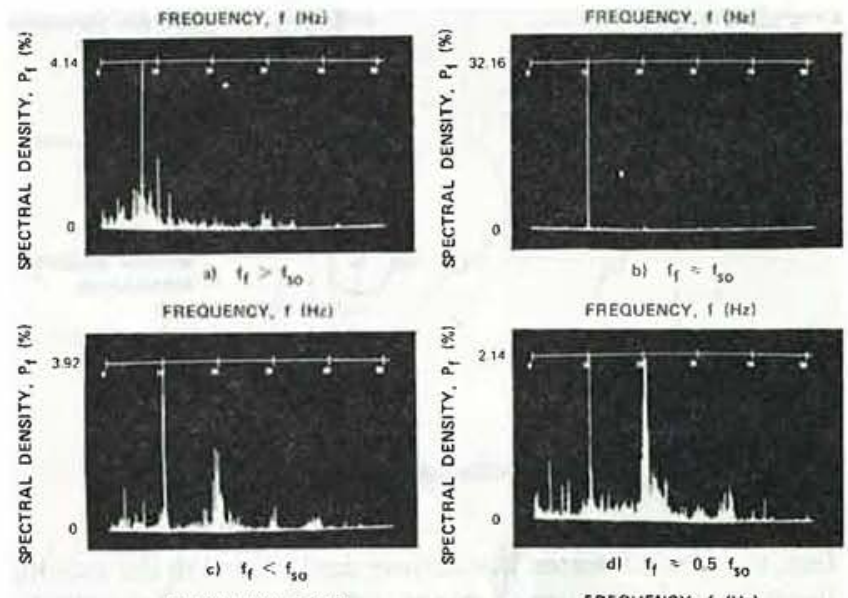

FREQUENCY, $f(\mathrm{~Hz})$
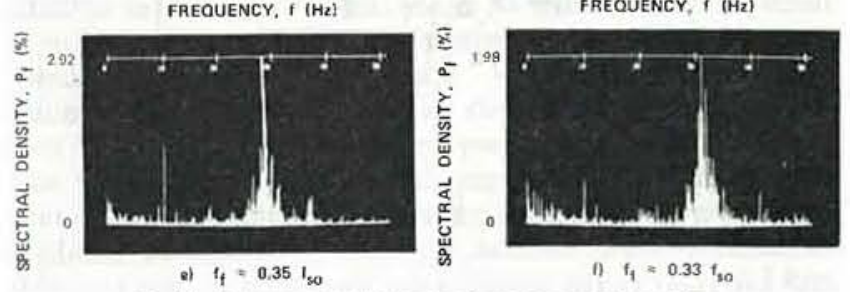

i) $f_{1}=0.33 t_{30}$

Fig. 6 Power spectra for various frequency ratios

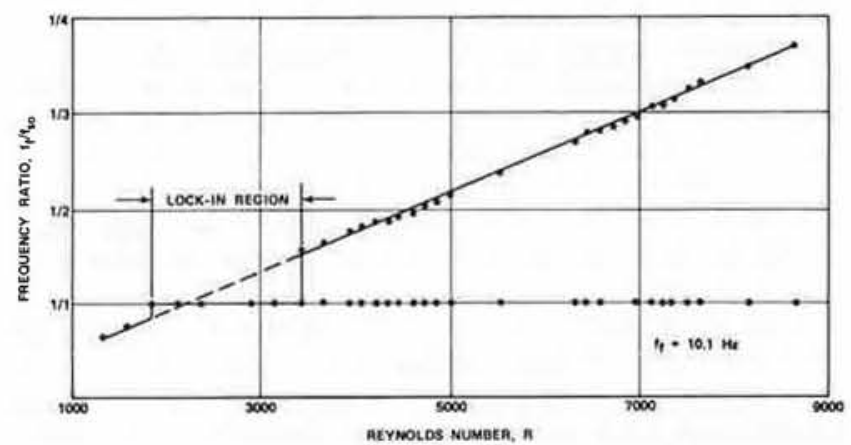

Fig. 7 Wake response for various tree stream velocities

vibration amplitude. This response probably resulted from the low reduced damping used, which would explain why no other investigators have distinctly observed the phenomena. If the free oscillation and forced oscillation situations are fluid mechanically equivalent, then, under the hypothesis that a low frequency vortex street was formed, the shedding frequency should have been entrained to the forced oscillation frequency near $f_{f} / f_{s o}=0.33$. This was not found to be true and, in fact, most of the energy associated with fluctuating wake velocities was found at $f_{\text {so }}$.

The lower mode response could have been subharmonic excitation by the (higher) vortex shedding frequency. In ef- 
$\longrightarrow$ LATERAL VELOCITY OF CYLINDER

$\Longrightarrow$ FLUID FORCE ON CYLINDER
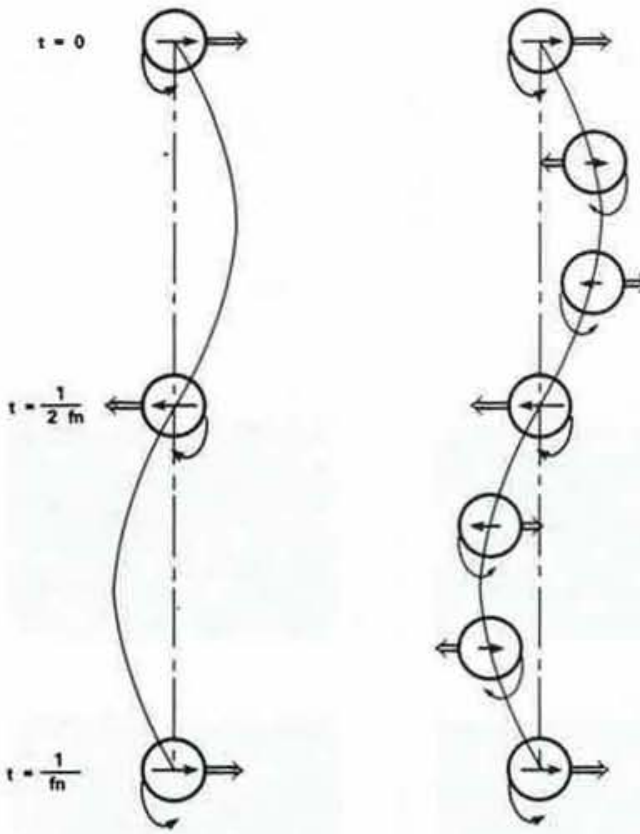

Fig. 8 Vortex shedding at $f_{n} \approx f_{\text {so }}$ and $f_{n} \approx f_{\text {so }} / 3$

fect, every third vortex would have contributed to the exciting force for half of a cycle. Since the spring-mounted cylinder vibrated in two modes with an effective frequency ratio of approximately $5 / 16=0.31(0.29$ average by actual calculation for each test) rather than 0.33 , the Strouhal number would have to have decreased from 0.21 to 0.19 over the Reynolds number range 1000 to 8000 . This behavior was, in fact, verified using spectral analysis of the wake of a rigidly mounted cylinder. Similar behavior was found by Lienhard and Liu [12]. In the present case, the variation was probably due to the sidewall treatment and its effect on base pressure as well as the free stream turbulence variation with tunnel speed. More peculiarly, the spring-mounted cylinder did not respond at a frequency ratio $f_{f} / f_{\text {so }}=0.50$ as found by Toebes [10] and Linenhard and Liu [12]. Effectively for this mode, every other shed vortex of the same sign would contribute to the exciting force for half of a cycle. The spectral analysis, however, for the cylinder undergoing forced oscillation near $f_{f} / f_{\text {so }}=0.50$ indicated conditions similar to $f_{f} / f_{s o}=0.33$. So, explanation in terms of subharmonic response cannot be altogether consistent either.

A vortex shedding sequence which encompasses aspects of both the low frequency vortex street hypothesis and the subharmonic response hypothesis is depicted in Fig. 8. During fundamental mode response, which is shown for comparison, vortex shedding is enhanced by motion of the cylinder. The lateral velocity promotes separation causing a vortex to form. The resulting force thus bears the proper relationship to the velocity.

Basically, the same sequence can occur with two intervening vortices added. The extra vortices are located at positions in the cycle such that separation is inhibited, thus resulting in weaker vortices. The ensuing forces do not act in the direction of motion and thus tend to retard motion. However, under conditions of small damping, as in the present study, sufficient energy is put into each half-cycle by every third vortex to overcome damping and the retarding force of the intervening vortices. Velocity fluctuations in the wake would exhibit frequencies of $f_{s o}$ and $f_{s o} / 3$. It would seem that there is no possible arrangement which can result in a similar sequence at $f_{s o} / 2$. In this case, of course, equation (1) cammol estimate the lift coefficients. Ericsson [25] has extended ilis, method of description to explain other lateral modes as woll a. in-line modes experimentally observed by Wootten, et al. $|2(1)|$ and King [1].

\section{Conclusions}

Lower mode response of elastically mounted cylinders ncu! $f_{n}=f_{\text {so }} / 3$ can occur providing damping is small. Syi chronization over finite bandwidth (lock-in) was not ol served, however.

Similar response was not found for $f_{n}=f_{s o} / 2$.

A conceptual model which combines some features of a low frequency vortex street with subharmonic response can bi used to explain lower mode response and the difference in observed behavior at $f_{s o} / 2$ and $f_{s o} / 3$.

\section{References}

1 King, R., "A Review of Vortex Shedding Research and its Application. Ocean Engineering, Vol. 4, 1977, pp. 141-171.

2 Bishop, R. E. D., and Hassan, A. Y., "The Lift and Drag Forces on. Circular Cylinder Oscillating in a Flowing Fluid," Proceedings of the Ronit Society (London), Series A, Vol. 277, 1964, pp. 51-75.

3 Koopmann, G. H., "The Vortex Wakes of Vibrating Cylinders at I in Reynolds Numbers," Journal of Fluid Mechanics, Vol. 28, Part 3, 1967, pl 501-512.

4 Toebes, G. H., and Ramamurthy, A. S., "Fluidelastic Forces on Circula Cylinders," Journal of the Engineering Mechanics Division, Proceedings of th. American Society of Civil Engineers, Vol. 93, EM 6, 1967, pp. 1-20.

5 Jones, G. W., "Unsteady Lift Forces Generated by Vortex Shedeliiı About a Large, Stationary and Oscillating Cylinder at High Reynolds NuI! bers," ASME Paper No. 68-r̈E-36, 1968.

6 Blevins, R., "Vortex Induced Vibration of Circular Cylindrical Stru tures," ASME Paper No. 72-WA/FE-39, 1972.

7 Hartlen, R. T., and Currie, 1. G., "Lift-Oscillator Model of Vortes Induced Vibration," Journal of Engineering Mechanics, Proceedings of the American Society of Civil Engineers, Vol.96, EM 5, 1970, pp. 577-591.

8 Skop, R. A., and Griffin, O. M., "An Heuristic Model for Determininy Flow-Induced Vibrations of Offshore Structures," OTC 1843, Offshor Technology Conference, Dallas, Texas, 1973.

9 Iwan, W. D., and Blevins, R. D., "A Model for Vortex Induccil Oscillation of Structures," ASME Journal of APpled Mechanics, Vol. $\%$ 1974, pp. 581-586.

10 Toebes, G. H., "The Unsteady Flow and Wake Near an Oscillatin. Cylinder," ASME Journal of Basic Engineerino, Vol. 91, No. 3, 1969, IM 493-505.

11 Penzien, J., "Wind Induced Vibration of Cylindrical Structures," Journal of the Engineering Mechanics Division, Proceedings of the Americill Society of Civil Engineers, Vol. 83, EM1, Jan. 1957, pp. 1-17.

12 Lienhard, J. H., and Liu, L. W., "Locked-In Vortex Shedding Behind Oscillating Circular Cylinders, with Application to Transmission Lines," ASME Paper 67-FE-24, Presented at the Fluids Engineering Conference Chicago, Illinois, May 8-11, 1967.

13 Gowing, S., "An Investigation of the Aeolian Converter as a Powei Generator," Report prepared for NSF-URP GY 1180, Worcester Polytechnic Institute, 1974.

14 Taneda, S., "Downstream Development of the Wakes Behind Cylin. ders," J. Phys. Soc. Japan, Vol. 14, 1959, pp. 843-848.

15 Durgin, W. W., and Karlsson, S. K. F., "On the Phenomenon of Vortex Street Breakdown," Journal of Fluid Mechanics, Vol. 48, 1971, pp. 507-527

16 Thomas, D. G., and Kraus, K. A., "Interaction of Vortex Streets," Journal of Applied Physics, Vol. 35, No. 12, 1964.

17 Zdravkovich, M. M., "Smoke Observations of the Wake of a Group of Three Cylinders at Low Reynolds Number," Journal of Fluid Mechanics, Vol. 32, Part 2, 1968, pp. 339-351.

18 Acton, E., "The Modeling of Large Eddies in a Two-Dimensional Shear Layer," Journal of Fluid Mechanics, Vol. 76, Part 3, 1976, pp. 561-592.

19 Christiansen, J. P., and Zabusky, N. J., "Instability, Coalescence, and Fission of Finite-Area Vortex Structures," Journal of Fluid Mechanics, Vol. 61, Part 2, 1973, pp. 219-243.

20 Griffin, O. M., and Votaw, C. W., "The Vortex Street in the Wake of : Vibrating Cylinder," Journal of Fluid Mechanics, Vol. 51, Part 1, 1972, pp. 31-48.

21 Stasaitis, J. F., "The Interaction of Elastically Mounted Cylinders with Secondary Vortex Streets," M.S. thesis, Worcester Polytechnic Institute, 1976. 22 Lefebvre, P. J., "An Investigation of Primary and Secondary Vortex Street Lock-In,"M.S. thesis, Worcester Polytechnic Institute, 1977.

23 Blevins, R. D., and Burton, T. E., "Fluid Forces Induced by Vortex Shedding," ASME Journal of Fluids Engineering, Vol. 98, 1976, pp. 19-24. 24 Blevins, R. D., Flow Induced Vibration, Van Nostrand Reinhold Company, New York, 1977. 
25 Ericsson, L. E., and Reding, J. P. "Vortex-Induced Asymmetric Loads on Slender Vehicles," Report LMSC-D630807, Lockheed Missiles and Space ('ompany, Inc., Sunnyvale, Calif., Jan. 1979.
26 Wootton, L. R., Warner, M. H, and Cooper, D. H., "Some Aspects of the Oscillations of Full-Scale Piles," IAHR Symposium on Flow Induced Structural Vibrations, Karlsruhe, Germany, 1972.

\section{I S C U S S I O N}

L. E. Ericsson. ${ }^{3}$ The interesting results obtained by Durgin, ot al. [27], for subharmonic response to Karman vortex thedding on a cylinder in crossflow are very much in agreement with the findings in a recently completed analysis of vortex-induced asymmetric loads [28]. In Fig. 1 the case $f$ - $f_{v 0} / 2$ has been added to Fig. 8 of reference [27], to Illustrate the effect of the translatory deflection. The situation In Fig. 1 is analogous to that existing for a pitching airfoil [29]. The moving wall has a wall-jet-like effect on the boundary layer development between stagnation and isparation points. The downstream moving wall delays reparation and causes a large overshoot of static lift maximum on a pitching airfoil [29]. The upstream moving wall effect is to promote separation. This adverse effect is oven more powerful than the beneficial effect of the downmtream moving wall, as is demonstrated by Swanson's results for a rotating cylinder [30]. Returning to Fig. 1 it can be seen that for $f=f_{v 0}$ at each vortex shedding event, alternating between top and bottom sides of the cylinder, the upstream moving wall effect promotes separation, thus onhancing the vortex-induced transverse force and causing the observed strong translatory response of the cylinder to the Karman vortex shedding [27]. At $f=f_{v 0} / 2$, however, the Iranslatory velocity-moving wall effect is zero for the vortex ahedding events taking place at maximum deflection. And at ncro deflection, where the moving wall effect is maximum, it alternates between enhancing and opposing the vortex whedding, explaining why no cylinder response to the vortex whedding was observed at this frequency [27]. Finally, for $f$ $=f_{10} / 3$, the maximum moving wall effect obtained at zero

J'Lockheed Missiles and Space Co., Inc., Sunnyvale, Claif.

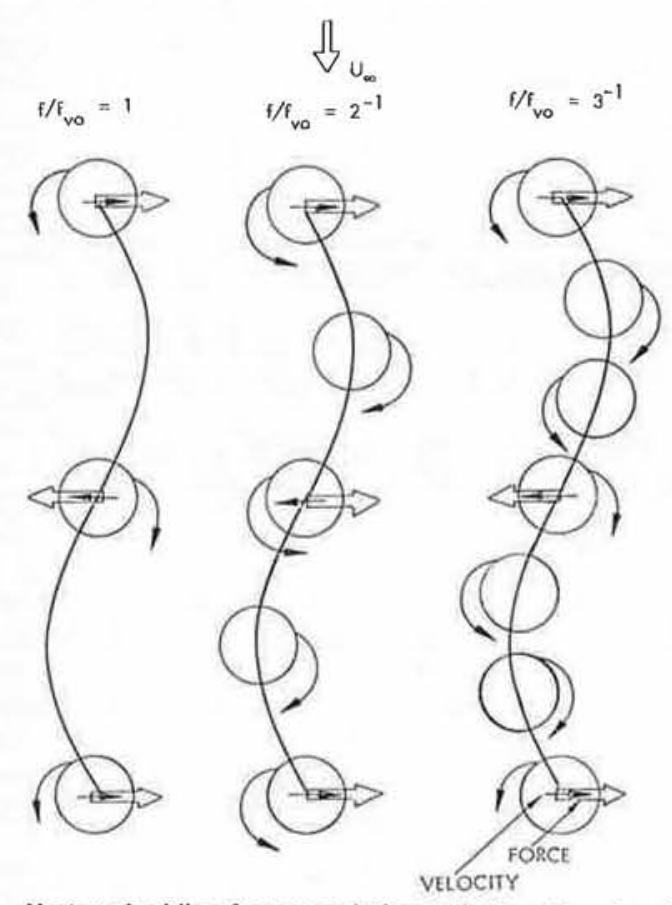

Pig. 1 Vortex shedding from translating cylinder at $f=t_{v 0}, t=t_{v_{0}} / 2$ and $F=t_{v 0} / 3$

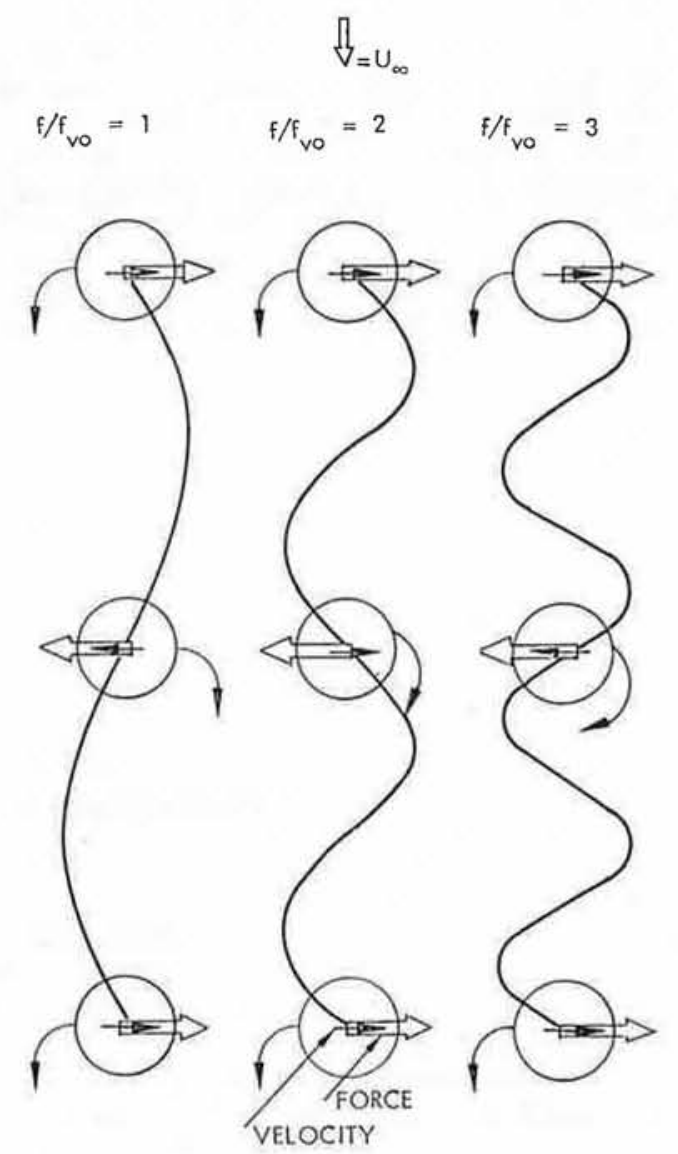
Fig. 2 Vortex shedding from translating cylinder at $f=f_{v 0}, t=2 f_{v 0}$
and $f=3 f_{v 0}$
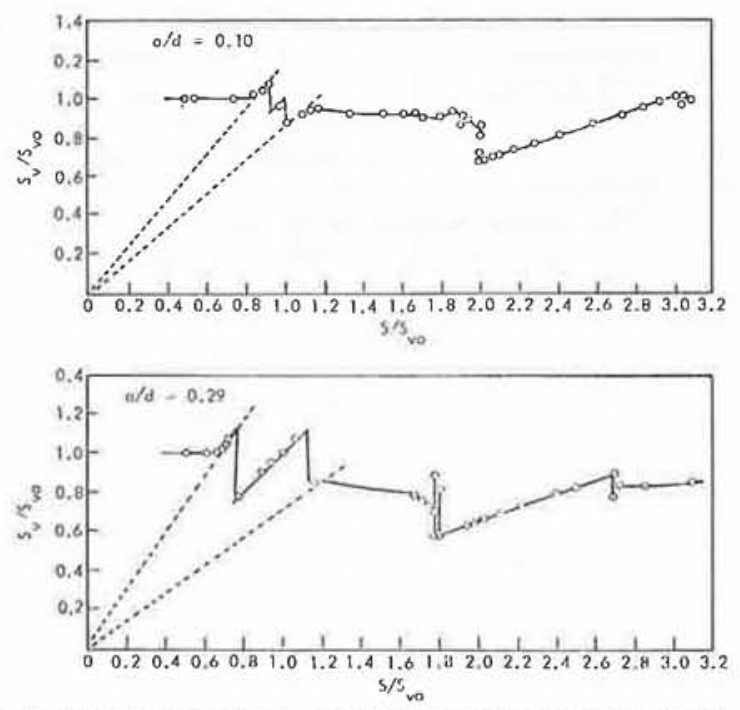

Fig. 3 Effect of translatory oscillation on cylinder vortex shedding 
deflection always enhances the vortex shedding, as in the case of $f=f_{10}$. For the intermediate pair of vortex shedding events occuring at near maximum deflection the translatory velocity with associated moving wall effect is very small. In addition, as was pointed out in reference [27], the (moving wall) effects are of opposite signs further diminishing the net effect of these two intermediate vortex shedding events at near maximum deflection.

Thus, one can see how the moving wall effect associated with the translatory oscillations can explain the observed subharmonic response at $f=f_{20} / 3$ and the absence of any response at $f=f_{t 0} / 2$. What about the superharmonic response? Figure 2 shows how in the case $f=3 f_{t 0}$ every vortex shedding event is enhanced by the moving wall effect, whereas for $f=2 f_{t 0}$ every other event is opposed by the translatory velocity effect. Thus, one would expect that locking-on of the vortex shedding phenomenon is possible at $f$ $=f_{t 0}$ and $f=3 f_{i 0}$, but not for $f=2 f_{t 0}$. This is exactly what the results obtained by Stansby [31] show (Fig. 3). There are lock-ins at $S_{c}=S_{0}$ and $S_{c}=3 S_{0}$, but no clear sign of locking-on at $S_{c}=2 S_{0}$.

\section{Additional References}

27 Durgin, W. W., March, P. A., and Lefebvre, P. J., "Lower Mitu Response of Circular Cylinders in Cross Flows," ASME Winter Aninet Meeting, San Francisco, Dec. 11-15, 1978, Nonsteady Fluid Dymamics Vohien pp. 193-200.

28 Ericsson, L. E., and Reding, J. P., "Vortex-Induced Asymmetric I enst on Slender Vehicles," Contract N60921-77C-0234, Report LMSC-D630ail Dec. 1978, Lockheed Missiles and Space Company, Sunnyvale, Callf.

29 Ericsson, L. E., and Reding, J. P.. "Dynamic Stall Analysis in Liehir Recent Numerical and Experimental Results," Journal of Aircraft, Vol i) No. 4, Apr. 1976, pp. 248-255. (Also AlAA Paper No. 75-26)

30 Swanson, W. M., "The Magnus Effect: A Summary of Investigation! Date," ASME Journal of Basic Engineering, Sept. 1961, pp. 461-470.

31 Stansby, P.K., "The Locking-on of Vortex Shedding due to Cross-Sluet Vibration of Circular Cylinders in Uniform and Shear Flows," Journal Fluid Mechanics, Vol. 74, Part 4, 1976, pp. 641-665.

\title{
Call for Fluids Engineering General Interest Papers
}

\author{
Joint ASCE-ASME Mechanics Conference \\ Boulder, Colorado \\ June 22-24, 1981
}

Prospective authors for papers of general interest to the Fluid Engineering Division of ASME for the subject conference should be submitted to:

\author{
Dr. Frank M. White \\ Editor, Journal of Fluids Engineering \\ University of Rhode Island \\ 222 Wales Hall \\ Kingston, Rhode Island 02881
}

The papers should be marked that the author desires to give the paper at the subject conference. Papers of general interest could be on the following subjects: fluid machinery, polyphase flow (includes cavitation), fluid transients, and fluid mechanics in general.

The format for submission of papers is equivalent to that specified for journal papers on the inside back cover of this issue. All general interest papers for the conference will be routed through associate editors of the journal.

To ensure completion of the review process for the conference manuscripts should be received approximately October 1, 1980. Authored prepared mats for accepted papers will be due at the above address by February 15, 1981. 